\title{
A COMPREENSÃO DA LEITURA DE SIGNWRITING POR ALUNOS SURDOS $* * *$
} THE UNDERSTANDING OF SIGNWRITING READING BY DEAF STUDENTS

Vinicius Rodrigues da Silva ${ }^{1}$ Gabriela Otaviani Barbosa ${ }^{2}$ Marianne Rossi Stumpf ${ }^{3}$

\author{
Recebimento do texto: 08/04/2018 \\ Data de aceite: 17/05/2018
}

RESUMO: Este artigo apresenta a compreensão da leitura de SignWriting por alunos surdos. Esta pesquisa teve como objetivo observar os alunos surdos se expressando naturalmente em Libras de acordo com sua compreensão no momento de leitura do livro literário "Cinderela surda" com SignWriting. Além disso, trabalha com as teorias de Stumpf (2005), Capovilla et al. (2006), Silva (2009), Nobre (2011), Kogut (2015), Wanderley (2015) e Barbosa (2017), os quais discutem sobre o tema abordado. Buscamos apontar alguns resultados obtidos pelos alunos surdos que apresentaram variações na produção dos sinais em seu processo de leitura de SignWriting constatadas pela compreensão dos sinais escritos na literatura surda em parte inseridos no livro literário. Por fim, suas visualizações nas pilhas por SignWriting representam compreensões dos signos de erro e de acertos, indicando a necessidade de uma melhor construção na escrita de sinais e na estrutura textual do livro literário.

PALAVRAS-CHAVE: Compreensão; Leitura; Surdos; SignWriting; Literatura surda.

ABSTRACT: This article presents the reading comprehension of SignWriting by deaf students. This research has as purpose to observe the deaf students expressing themselves naturally in Libras (Brazilian Sign Language) according to their comprehension at the reading moment of the book "Cinderela surda" with SignWriting. In addition, the article considers the theories of Stumpf (2005), Capovilla et al. (2006), Silva (2009), Noble (2011), Kogut (2015), Wanderley (2015) and Barbosa (2017), who discuss the mentioned topic. We seek to point some results obtained by the deaf students who showed variations in the signs' production in their process of SignWriting reading noticed by the understanding of the signs written in the deaf literature inserted in part in the literary book. Finally, their views on "stacks" by SignWriting represent an understanding of the signs of mistakes and successes. This fact indicates the need for better construction in sign writing and the textual structure of the literary book.

KEYWORDS: Understanding; Reading; Deaf people; SignWriting; Deaf literature.

${ }^{1}$ Professor do Colégio Estadual Maurício Murgel. Graduado em Letras Libras pela Universidade Federal de Goiás (UFG).

${ }^{2}$ Professora da Universidade Federal do Tocantins (UFT). Mestra em Linguística Aplicada pela Universidade Federal de Santa Catarina (UFSC).

${ }^{3}$ Professora da Universidade Federal de Santa Catarina (UFSC). Doutora em Informática na Educação pela Universidade Federal do Rio Grande do Sul (UFRGS).

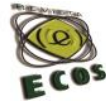




\section{Introdução}

O presente trabalho intitulado "A compreensão da leitura de SignWriting por alunos surdos" se justifica pela compreensão limitada por alunos surdos na leitura de textos escritos em português, e estes, em sua totalidade, estão presentes em todo o ambiente e níveis de ensino: desde o ensino básico até o superior. Este trabalho se torna importante, pois visa provocar maior produção de literatura sobre o tema e também um maior número de publicações em SignWriting ${ }^{\mathrm{i}}$.

O objetivo desta pesquisa é observar os alunos surdos ao se expressarem naturalmente em Língua Brasileira de Sinais (Libras) no momento da leitura de livro literário em SignWriting. Para tanto, se faz necessário investigar as causas do problema, isto é, da compreensão; descobrir se os dados são representativos, e mostrar os resultados mais concretos e menos possíveis de erros das pilhas ${ }^{\mathrm{ii}}$ em SignWriting e identificar os princípios e os procedimentos sistemáticos para a transformação de livros em diversos gêneros textuais mais esclarecidos para a comunidade surda.

Na hipótese sugere-se observar o aluno surdo especificamente com experiência de leitura e compreensão textual para seu melhor aprendizado a partir da escrita de sinais SignWriting formulando as seguintes perguntas: qual o nível de facilidade na compreensão das pilhas apresentadas na leitura para cada produção literária apresentada, através de sistema SignWriting? A estrutura do texto em SignWriting pode qualificar essa compreensão na leitura? 
Com base nos dados que serão observados, com relação ao estudo descritivo, buscaremos por fenômenos que mostram se há desvantagem e vantagem na compreensão da leitura dos alunos surdos, para isso será utilizado texto do livro literário em SignWriting. Assim, a observação se dará com análise tanto da qualidade da literatura surda como da alfabetização ${ }^{\text {iii }}$ nas pilhas, levando em consideração a estrutura de sistema de registro da Libras.

Além dessas questões, pretende-se levantar resultados no processo de análise e discussão e determinar assim uma proposta para transmissão de conhecimento cultural nas práticas atuais da alfabetização e do letramento dos surdos.

O livro literário registrado do sistema SignWriting ajuda os surdos no desenvolvimento da aquisição de linguagem que, com a compreensão da língua de sinais, reconhece a língua dos surdos. O aluno surdo quando lê textos em português não consegue entender o significado de diversas palavras, porém, elas podem ser representadas e compreendidas no sistema SignWriting.

Neste contexto, o livro textual é apresentado na versão em português e traduzido para a Libras, com foco na alfabetização pelo sistema de SignWriting. É desenvolvido de forma experimental, motivando a leitura e escrita da própria língua de sinais no sentido dos signos. Pois, a partir disso, o aluno surdo aproveita para buscar a leitura de textos espontâneos do livro.

A formação dos signos é o processo da alfabetização na Libras, e o texto através do sistema de SignWriting representando a língua de sinais 
para o aluno surdo significa a transmissão de sinais. Esse texto da alfabetização no livro literário através de SignWriting tem as pilhas que representam cada parâmetro. A expressão dos textos em SignWriting segue auxiliando em uma alfabetização significativa para os alunos surdos como primeira língua (L1).

O letramento difere de o simples ler e escrever porque pressupõe um entendimento do uso apropriado dessas capacidades dentro de uma sociedade que está fundamentada no texto impresso. Assim a lectoescrita requer um envolvimento autônomo e ativo com o texto impresso e destaca o papel do indivíduo no gerar, receber e atribuir interpretações independente às mensagens (STUMPF, 2005, p. 36).

O processo de letramento é extremamente importante, pois gera a aprendizagem de leitura e escrita e pode ser apresentado com textos utilizando-se do sistema SignWriting, e este pode também registrar a língua dos surdos, o que motiva e desenvolve a compreensão com facilidade. $\mathrm{O}$ texto impresso no livro literário através de SignWriting deve mostrar uma transmissão bilíngue à comunidade surda, desde o ensino básico até a faculdade. Desse modo, desenvolve-se a aprendizagem dos alunos surdos, que ao lerem o real sentido dos signos por completo, e ao representarem de forma escrita o conhecimento, poderão, assim, se apresentar como "sujeitos culturais", isto é, praticarão na produção textual simultaneamente o português e a Libras. 


\section{Sistemas de Escritas das Línguas de Sinais}

Barreto e Barreto (2012, p. 34-39) apresentam sistemas de escrita que representam as línguas de sinais:

Notação mimographie: foi publicada em 1822 por Roch Ambroise Auguste Bébian (1789-1839), educador francês [...].

Notação de William C. Stokoe: linguista e pesquisador norteamericano, Stokoe (1919-2000) foi o primeiro a reconhecer como naturais as línguas de sinais [...].

Hamburg Notation System (HamNoSys): conforme Hanke (2004), o HamNoSys é baseado no sistema de Stokoe e teve sua primeira versão definida em 1984 [...].

Sistema D'Sign: Paulo Jouison (1948-1991) criou o D'Sign em meados de 1990 ampliando a ideia de Stokoe (1965) e aplicando o método à Língua de Sinais Francesa, porém, Jouison faleceu antes de apresentar seu trabalho [...].

Notação de François Neve: pesquisador na Universidade de Liége na Bélgica, Neve desenvolveu este sistema em 1996 a partir do sistema de Stokoe (1965) [...].

Sistema de Escrita das Línguas de Sinais (ELiS): foi criado em 1997 pela $\mathrm{Dr}^{\mathrm{a}}$. Mariângela Estelita Barros e aprimorado em 2008 [...].

Sistema de escrita SignWriting: foi criado pela norteamericana Valerie Sutton na Dinamarca em 1974. No anterior, Sutton havia criado um sistema para escrever passos de dança chamado DanceWriting e estava na Dinamarca ensinando-o em uma escola de dança. Um jornal local publicou um artigo sobre esta escrita e isto chegou ao conhecimento de pesquisadores da Língua de Sinais Dinamarquesa da Universidade de Copenhagen que estavam buscando uma forma de escrevê-la. Assim, solicitaram a Sutton que escrevesse as sinalizações disponíveis em vídeo de alguns surdos. Foi então que, adaptando seu sistema de escrita, nasceu o SignWriting, um sistema específico para escrever as línguas de sinais (SUTTON, 1999) [...].

Atualmente foram divulgados à comunidade surda do Brasil os três sistemas da escrita de sinais: SignWriting, ELiS e SEL ${ }^{\text {iv }}$, que registra a 
Libras. Neste tipo de estudo foi adotado o SignWriting por ser mais conhecido e desenvolvido por algumas instituições ${ }^{\mathrm{v}}$ e também pela quantidade $^{\mathrm{vi}}$ de livros publicados.

\section{A escrita}

O sistema SignWriting apresenta uma estrutura simbólica escrita para configuração da mão, orientação da palma, ponto de articulação, contato com movimento e expressões faciais que são utilizados para representação do registro de língua de sinais. Na parte da escrita e leitura que o sistema desenvolve, a alfabetização na escrita de sinais é um processo de ensino-aprendizagem para que os surdos codifiquem símbolos escritos e verifiquem pilha pela representação da Libras e também para compreenderem, pela codificação dos signos, o significado das palavras.

Muitos surdos iniciam sua alfabetização pela língua portuguesa, sem conhecerem ainda a escrita de símbolos atribuídos à língua de sinais, razão muitas vezes da não compreensão do significado das palavras. A escrita alfabética e língua de sinais possuem estruturas diferentes. Durante muito tempo a maioria dos surdos não conseguia compreender e assimilar a língua escrita do português e sentia dificuldade sem o apoio da língua de sinais. Na alfabetização do português, o ensino-aprendizagem com codificação e decodificação fonológica da fala produz para o aluno ouvinte a leitura na escrita alfabética, o que não acontece com o aluno surdo. Portanto, é primordial para o surdo o aprendizado da língua de sinais como a primeira língua a ser apresentada e, a língua portuguesa como a segunda 
para seu aprendizado (CAPOVILLA et al., 2006 apud BARRETO; BARRETO, 2012; WANDERLEY, 2015).

\begin{abstract}
Um exemplo desta situação encontramos quando alunos de escola para surdos fazem demonstrações artísticas de sua potencial capacidade de articular fonemas em palavras e estas em frase e versos. Tais comportamentos robotizados, exibidos pelos surdos a grandes plateias reunidas para testemunharem o sucesso da educação, reforçam a deficiência e geram expectativas nestes sobre a normalização através da aquisição de uma língua morta (o português para surdo), mas com poder de domínio cultural (WANDERLEY, 2015, p. 48).
\end{abstract}

O desenvolvimento cognitivo dos surdos difere dos ouvintes, porém não os torna incapazes ou impossibilitados, mas sim alunos surdos com possibilidades de aquisições diferentes das duas línguas. Contudo, reforça-se a aquisição de linguagem na língua de sinais como primeira língua (L1) ser apresentada aos surdos possibilitando assim uma maior capacidade de comunicação e de aquisição de linguagem na sua segunda língua (L2), o português. Capovilla et al. (2006, p. 1494 apud BARRETO; BARRETO, 2012, p. 33) destacam:

Do mesmo modo que a criança ouvinte pode beneficiar-se do uso de uma escrita alfabética para mapear os fonemas de sua língua falada, a Surda poderia beneficiar-se sobremaneira de uma escrita visual capaz de mapear os quiremas de sua Língua de Sinais.

Para Wanderley (2015) essas duas línguas possuem estruturas muito diferentes, pois existe uma palavra em português para vários sinais como classificadores, o que o português não tem, pois produz contextos 
ambíguos. A Libras não tem relação com a estrutura de escrita da língua portuguesa. A língua de sinais torna-se um sistema de escrita através de símbolos escritos como ideograma. No entanto, se os surdos forem aprender duas línguas, é importante que a base seja a escrita de sinais como primeira língua. Dessa forma é facilitada a aprendizagem, o entendimento da segunda língua, o português.

É importante fundamentar a representação da escrita própria da primeira língua, ou seja, a escrita de sinais, tendo o apoio de uma cultura própria na qual se possa perceber o profundo sentido da linguagem e vencer, com facilidade e assim ter a possibilidade de aprender outra escrita como segunda língua, que é o português (WANDERLEY, 2015, p. 49).

Sobre esse processo, Chomsky faz uma reflexão evidenciando a "criatividade governada por regras":

A primeira diz respeito à língua, à competência do falante enquanto sistema de regra, a segunda diria respeito à fala, à performance, aos múltiplos desvios individuais que poderiam suceder quando da realização da fala. É a "criatividade governada por regras" que caracteriza a atividade da linguagem como atividade infinita de um sistema de regras (CHOMSKY, 1979, p. 92 apud WANDERLEY, 2015, p. 50$51)$.

Para Chomsky, a língua de sinais é "fala" apropriada para surdos. Portanto, o sistema de escrita de sinais representa a relação que possui regra gramatical: fonética, sintática etc.; é estrutura sistematizada em ideogramas como escrito simbólico, caracterizando a atividade de linguagem como sistema regra. 
Stumpf (2012, p. 68) diz que "sentimos falta de uma literatura em escrita de sinais, histórias que despertem o interesse dos jovens, pois eles não acham graça em histórias infantis que são as que conseguem ler em português".

As pessoas surdas acham que não necessitam ler ou escrever um texto. Já outras negam o direito de ler ou escrever devido a traumas sofridos ao aprenderem, por obrigação, a escrever em português, sem subjetividade, e não associado à língua de sinais. Acham que falar em língua de sinais já é o suficiente para seu conhecimento em relação à comunicação e informações sobre esta língua. São analfabetos que "participam" de uma cultura letrada, por possuírem melhores informações em Língua de Sinais, sem dificuldades de entendimento para abrir a mente do que se alfabetizar (WANDERLEY, 2015, p. 51).

Na verdade, é importante estimular os surdos a escreverem e lerem através de escrita de sinais pela representação de língua de sinais na leitura do texto interpretando para o português. E, assim, chegar a uma maior compreensão espontânea dos signos e competência para entender o significado.

O processo cognitivo dos surdos no desenvolvimento linguístico passa pela comunicação em língua de sinais como linguagem visual no fortalecimento da identidade e cultura surda, possibilitando habilidades de escrita de sinais no texto (STUMPF, 2005; SILVA, 2009; CAPOVILLA et. al., 2006 apud BARRETO; BARRETO, 2015).

Wanderley (2015, p. 53) afirma que:

Além de garantir a preferência da língua falada como em Libras temos que enfrentar a luta para mudar a visão sobre a escrita para conhecer tanto a si mesmo quanto pelo ato de escrever e desenvolvido com liberdade de ação.

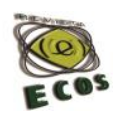


Em relação ao sistema de escrita de língua de sinais no papel para surdos, Silva (2009) acrescenta:

O uso do sistema de escrita SignWriting, assim como outras escritas, se constitui como estratégia de construção de significados e método de estudo, pois facilita a lembrança e a recuperação da informação guardada na memória. Atualmente a maioria dos surdos tem acesso aos conteúdos escolares através da tradução por um intérprete de Libras, porém, os conteúdos são escritos em Língua Portuguesa, o que não contribui para memorização, lembrança e associação com outros conhecimentos. Não há uma forma de registro acessível que se possa consultar (SILVA, 2009, p. 53 apud BARRETO; BARRETO, 2015, p. 87).

Sobre o bilinguismo:

Parte do princípio de que o surdo deve dominar, enquanto língua materna, a língua de sinais, que é a sua língua natural, e como L2 a língua oficial de seu país. Nesse sentido, é de fundamental importância o convívio da criança surda com outros surdos mais velhos, que dominem a Língua de Sinais (NOBRE, 2011, p.50).

No entanto, o processo de bilinguismo de alfabetização na escrita de sinais apresenta o português e o leitor surdo sempre tende a compreender a primeira codificação na escrita de língua de sinais apresentando num modo de pilhas em SignWriting como primeira língua. Além disso, português entende decodificação nesse escrito ao transferir para uma pilha compreensível numa aquisição da linguagem como segunda língua. 


\section{A leitura}

A leitura desenvolvida no ambiente escolar para os surdos deve ser através da escrita de sinais pela representação visual da língua de sinais no texto.

$\mathrm{Na}$ sociedade atual as pessoas que vivem nas cidades são reféns da leitura. É necessário saber ler as placas de ônibus, números, etiquetas de alimentos, documentos, enfim, a leitura é fundamental para a vida cotidiana. Nesse sentido, ler é uma atividade tão importante quanto produzir textos (KOGUT, 2015, p. 38).

Então, é importante também a leitura natural para surdos. Silva (2002, p. 200) diz que "em muitos casos o surdo lê, mas não entende o que lê, não consegue construir o sentido do texto, têm o costume de ler as palavras isoladamente sem considerar seu contexto, costuma-se sempre buscar a tradução para a língua de sinais".

Por outro lado, há problemas também com a leitura de palavras que representam sons de falas, pois o surdo não consegue entender o significado. Stumpf (2012, p. 62-63) afirma que:

A criança ouvinte, quando vai para a escola, já conhece o significado das palavras. Quando ela aprende a ler, sabe o que as palavras significam, pois, o português escrito apresenta características da fala, assim como se fosse um retrato. Quando aprende a ler, a criança ouvinte vê esse retrato e o reconhece. Por outro lado, a criança surda não ouve a fala da família. Então, ela vai para a escola, aprende a ler, mas não consegue entender o que as palavras representam, ela não consegue reconhecer o retrato porque antes não ouviu a palavra associada à ação ou ao objeto. Por isso o surdo parece que sabe ler, mas não entende o significado.

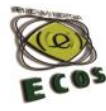


Na verdade, há muitos surdos que ao lerem uma questão de prova ou de qualquer texto não entendem seu significado, dificultando a formulação de uma resposta. Sempre questionam essa compreensão pedindo uma tradução na língua de sinais. O sistema de escrita de língua de sinais como SignWriting no texto de leitura dos surdos facilita o entendimento através dos signos.

\footnotetext{
Os resultados das análises mostram que ao ler em SignWriting, o leitor é capaz de associar informações já adquiridas às novas informações. Acrescentar, interpretar, resumir, tudo é possível nesta troca de informações entre o texto e o leitor na Língua de Sinais (SILVA, 2009, p. 99-100 apud BARRETO; BARRETO, 2012, p. 91).
}

No processo de leitura é enunciada linguagem que atribui entendimento dos signos e conhecimentos da escrita de sinais que o leitor surdo gera durante o desenvolvimento de sua alfabetização de SignWriting para compreender previamente o texto representado por Libras. Nessa forma de sistema de escrita de sinais, o SignWriting apresenta características com conhecimento linguístico diverso: fonético, fonológico, morfológico, sintático, semântico, pragmático e outros; contexto de pilha representa simultaneamente léxico e descrições imagéticas ${ }^{\text {vii }}$; o texto, elemento de estrutura de escrita de sinais segue ideograma, pilha e sistema dos signos. Essas características completam o desenvolvimento de letramento dos surdos.

Para o aluno surdo, é importante ler, reconhecer e interpretar língua de sinais que foi escrita em português. E, na sequência, escrever, planejar e produzir escrita de sinais que possa ser lido pelos signos. "Ler e escrever 
são processos estreitamente ligados. A leitura leva a um melhor desempenho na escrita, ambas estimulam o pensamento, a produção de diferentes textos melhora a compreensão da leitura” (SILVA, 2002, p. 202). “A relação entre as duas, de escrita e de leitura, deve estar unida como alfabetização e letramento, que não podem ser separados para não ocorrer uma formação defeituosa" (WANDERLEY, 2015, p. 59).

Ao contextualizar a compreensão constitui o objetivo da atividade de leitura, quaisquer ideias e informações explícitas dispostas no texto em SignWriting passam por um processo de compreensão que se o aluno surdo precisa saber a interação de diversos níveis de conhecimento prévio como linguístico, patrimônio cultural, elementos da estrutura textual, conhecimento de mundo, consegue construir o sentido do texto em SignWriting pelos seus esquemas cognitivos e conhecimentos das circunstâncias da escrita de sinais que lhe permitem preencher as lacunas do texto, pois que devem relacionar em conta todas as informações explícitas recorrendo ao desenvolvimento de sua linguagem com certo nível de conhecimento prévio.

\section{Metodologia}

Este trabalho foi feito através de pesquisas científicas qualitativa e bibliográfica, que direcionam como objetivo investigar a apresentação estatística descritiva para coleta de dados e usa instrumentos estruturados e métodos específicos de compreensão e explicação. Minayo (2001), Fonseca (2002) e Gil (2007) afirmam que nessas áreas qualitativa e bibliográfica são 
feitas pesquisas científicas a partir do levantamento de referências teóricas analisadas e publicadas por meio de textos escritos e eletrônicos, como livros e sites, e investiga a descrição sobre ideologias ou aquelas que se propõem à análise das diversas posições acerca de um problema, para que assim possa fazer uso da observação a partir do livro literário apresentado através de SignWriting, da avaliação para obtenção de esclarecimentos, da opinião e, então, que se possa discutir o caráter de exploração, descobrir, descrever e compreender.

A pesquisa "A compreensão da leitura de SignWriting por alunos surdos" foi realizada através de investigação com os 4 (quarto) participantes que desenvolveram o sistema de escrita de sinas (SignWriting) e também motivados para a leitura.

O nosso instrumento de coleta de dados consistiu no material didático e na filmagem de expressões dos participantes. Na elaboração da filmagem, foram investigados os 4 (quarto) participantes surdos do curso de Letras Libras que já estudaram a disciplina de Escrita de Sinais (SignWriting) nas duas instituições: Universidade Federal de Santa Catarina (UFSC) e Universidade Federal de Pernambuco (UFPE).

$\mathrm{Na}$ pesquisa de material didático foi acessado, através do site do Google, o link viii do livro "Cinderela surda", que trata de uma literatura surda infantil do Brasil pela editora ULBRA, criado pelos pesquisadores Lodenir Becker Karnopp, Caroline Hessel e Fabiano Rosa e apresenta um conto tradicional com leitura de escrita de sinais (SignWriting), versão em português e com ilustrações. O livro contém 10 páginas, mas foram escolhidas apenas quatro partes para que cada participante pudesse realizar 
a leitura em escrita de sinais e sinalizar para a Libras. A escolha deste livro literário busca verificar se os participantes são capazes de compreender as estruturas dos textos em SignWriting sendo caracterizada sua compreensão da leitura pela produção em Libras.

Os quatro participantes surdos da pesquisa são: $1^{\circ}$ participante graduando em Letras Libras presencial pela UFPE, reside em RecifePernambuco; $2^{\circ}$ participante: formado em Letras Libras na graduação presencial pela UFSC, reside em Florianópolis -Santa Catarina; $3^{\circ}$ e $4^{\circ}$ participantes: graduados em Letras Libras a distância pela UFSC (polo Goiânia) e residem em Goiânia - Goiás.

Foi utilizada a câmera do aparelho celular, modelo Iphone 6, para gravar e registrar os participantes expressando em Libras o que foi lido em escrita de sinais (SignWriting).

As participações dos $1^{\circ}$ e $2^{\circ}$ alunos surdos aconteceram de modo virtual e foi utilizado o recurso de videochamada através do Hangouts alternativo do Gmail, foi enviado a eles por e-mail o livro "Cinderela surda”. E, ao acessarem a plataforma on-line foi solicitado que sinalizassem o que foi lido; as telas do notebook do pesquisador foram capturadas e gravadas através do Iphone mencionado acima. No encontro pessoalmente com o $3^{\circ}$ e $4^{\circ}$ participantes, foi solicitado que eles sinalizassem o que foi lido em escrita de sinais (SignWriting) para Libras ao realizarem a leitura do livro "Cinderela surda" por três vezes em que leram as frases diretamente de SignWriting em um sistema registrado deste livro literário da escrita da esquerda para direita durante a produção na sua compreensão da leitura. 
Em seguida analisamos as gravações dos participantes, organizamos em uma pasta no notebook e em uma tabela do Word, nela anotamos a escrita por sinalização de cada um, por fim, editamos os sinais escritos através do programa SignMaker alternativo do site de SignBank.

\section{Resultados e discussão}

$\mathrm{Na}$ análise dos dados foram consideradas as narrativas obtidas das sinalizações apresentadas pelos alunos surdos da pesquisa. Esses participantes surdos cursaram as disciplinas obrigatórias de Escrita de Sinais (Sistema SignWriting) I e II durante a graduação do curso de Letras Libras. Nas pesquisas descritivas consideramos as características dos alunos surdos que estabelecessem relações com a leitura feita de textos em SignWriting e sua representação em Libras, dentro da estrutura de textos literários. Na discussão, a partir da proposta da pesquisa, reportamos aos dados de notação escrita ${ }^{\text {ix }}$, discussão de análise e escolha do melhor texto literário impresso em SignWriting para alunos surdos.

Nos resultados dos dados de notações escritas obtidos pelos alunos surdos estes os produziram naturalmente, de acordo com a análise descritiva, os quatro participantes apresentaram seu processo da leitura de SignWriting constatado pela compreensão em ler codificações em pilhas por sinais escritos na literatura surda em partes do livro literário "Cinderela surda". Investigamos os possíveis erros na estrutura do sistema da escrita de sinais, o contexto dos signos na representação em Libras e a estrutura dos textos. A seleção foi feita de algumas páginas do livro e estas 
ISSN: 2316-3933

Online

apresentadas aos participantes da pesquisa para leitura dos escritos originalmente em SignWriting:

Figura 1 - Figuras do livro literário "Cinderela surda"
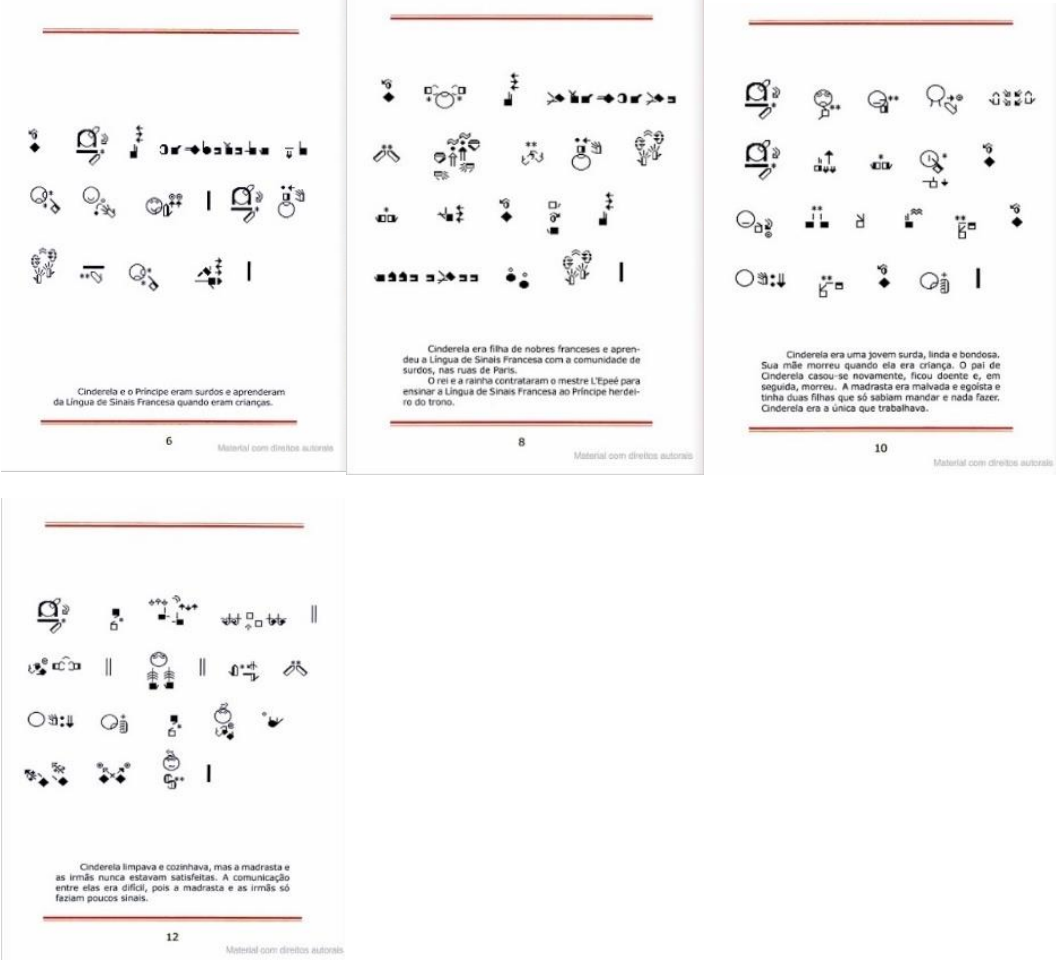

Fonte: Capturada pelos autores (2017).

Com essa análise descritiva dos dados foi possível uma investigação da notação escrita da narrativa em Libras: a verificação da codificação em Libras de cada sinal escrito foi feita com sua representação nas pilhas, considerando a compreensão dos signos e coesão textual. Além dessa notação escrita, houve a interpretação das narrativas em sinais de Libras a partir dos sinais escritos. 


\section{Análise dos dados}

$\mathrm{Na}$ análise dos dados, consideramos a visualização das pilhas por cada aluno surdo que apresentou as sinalizações compreendidas como respostas a partir dos sinais escritos originalmente em SignWriting em algumas páginas do livro literário "Cinderela surda". $\mathrm{Na}$ análise de discussão escolhida ocorreram variações entre acerto e erro das sinalizações dos dados que descrevem motivos de sinais escritos como NOME, BONITA, GOSTAR, CARINHO, APRENDER, CASTELO, BATISMO CINDERELA, MADRASTA, BATISMO IRMÃ CAÇULA, TRABALHAR, LAVAR PRATO e LAVAR CHÃO, foram identificados os parâmetros partindo do SignWriting do livro fenômeno determinado na conclusão. As tabelas dos dados de notação escrita mostram em primeiro lugar o sinal escrito registrado em SignWriting no livro literário "Cinderela surda", em segundo a foto do tradutor com o sinal escrito original para sinalização e em terceiro a notação escrita das sinalizações dos quatro participantes para sinal escrito.

Quadro 1 - Sinal: NOME

\begin{tabular}{|c|c|c|c|c|c|}
\hline $\begin{array}{l}\text { SignWritin } \\
g \text { Original }\end{array}$ & FOTO & P1 & P2 & P3 & P4 \\
\hline & & $\Longrightarrow$ & & & 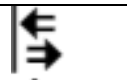 \\
\hline
\end{tabular}

Fonte: Elaborado pelos autores (2017). 
A pilha desse sinal NOME escrito em SignWriting representa só um movimento, mas a maioria dos participantes sinalizam vários movimentos. A pilha com representação desse sinal tem a mão esquerda à parede com movimentos de repente para direita e esquerda. Alguns participantes sinalizaram identificados movimentos diferentes: P1 apresentou a mão direita à parede em movimento uma vez para direita; P2, P3 e P4 apresentaram a mão direita à parede com movimento de repente para direita e esquerda e mesmo caminha uma vez para direita. Todos os participantes produziram expressões de sinalização de mão direita diferente do sinal escrito, que representa mão esquerda.

Quadro 2 - Sinal: BONITA

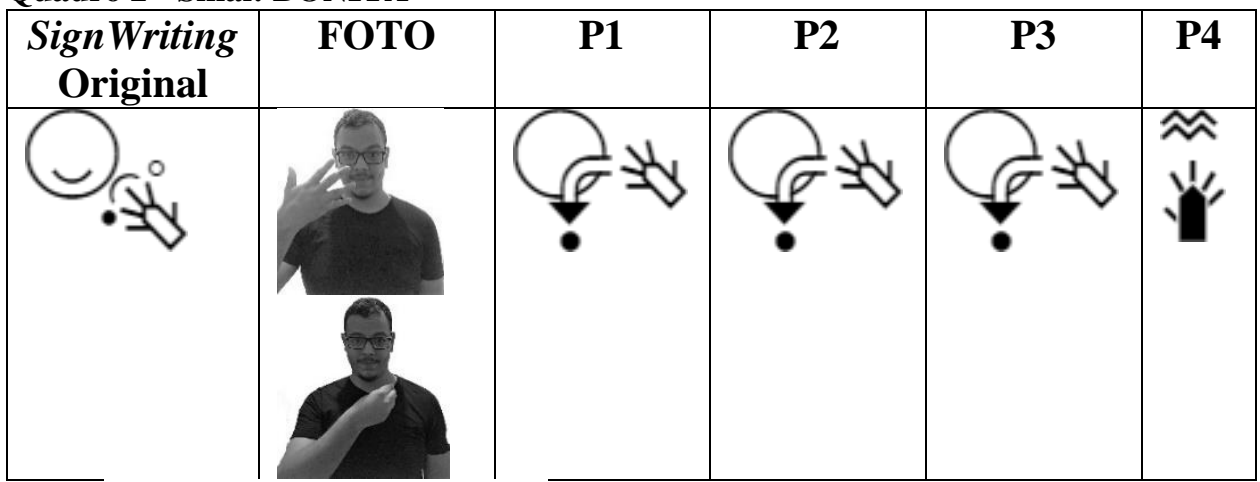

Fonte: Elaborado pelos autores (2017).

A representação do sinal BONITA escrito em SignWriting movimenta: a mão direita fecha e abre; abre e fecha. Apresentaram P1, P2 e P3 começando com a mão direita aberta fazendo movimento de arco para abrir e fechar. P4 apresentou movimentos de tamborilar dedos, não compreendendo. 
Quadro 3 - Sinal: GOSTAR

\begin{tabular}{|c|c|c|c|c|c|}
\hline $\begin{array}{c}\text { Sign Writin } \\
\text { g Original }\end{array}$ & FOTO & P1 & P2 & $\mathbf{P 3}$ & P4 \\
\hline & & e@ & eৎ & $* * \Gamma$ & $* * \geqslant$ \\
\hline
\end{tabular}

Fonte: Elaborado pelos autores (2017).

A pilha do sinal GOSTAR escrito em SignWriting apresenta a mão direita aberta em posição de contato que toca de repente o tórax. P1 e P2 apresentaram o sinal que tem representação em posição de contato, mas com a mão direita esfregando de repente o tórax, mas representando, claro, pois o tipo de contato está diferente ao escrito original de livro literário; P3 apresentou o mesmo sinal escrito original ao livro literário em SignWriting e P4 apresentou identificando configuração da mão: mão direita espalhada e contato que toca de repente o tórax pela representação de significado MEU.

Quadro 4 - Sinal: CARINHO

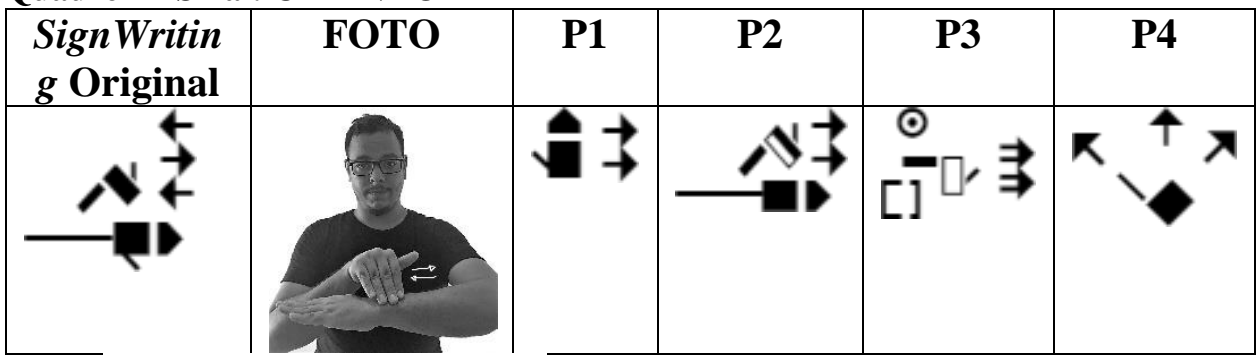

Fonte: Elaborado pelos autores (2017). 
A pilha do sinal CARINHO foi apresentada pelos participantes com vários sinais. P1 sinalizou CRIANÇA e percebe-se que não compreendeu. P2 sinalizou erroneamente, considerando a visualização no sinal escrito original e significou o termo CARINHO, ele identificou a orientação da palma com movimento diferente do original. P3 sinalizou CARINHO diferente do sinal escrito original e compreendeu o significado, sinalizou configuração da mão e orientação da palma para frente. P4 sinalizou VOCÊS, não compreendeu. Constata-se que esse sinal escrito original não ficou claro, porque na falta de contato e orientação da palma, houve uma dificuldade na compreensão da leitura.

\section{Quadro 5 - Sinal: APRENDER}

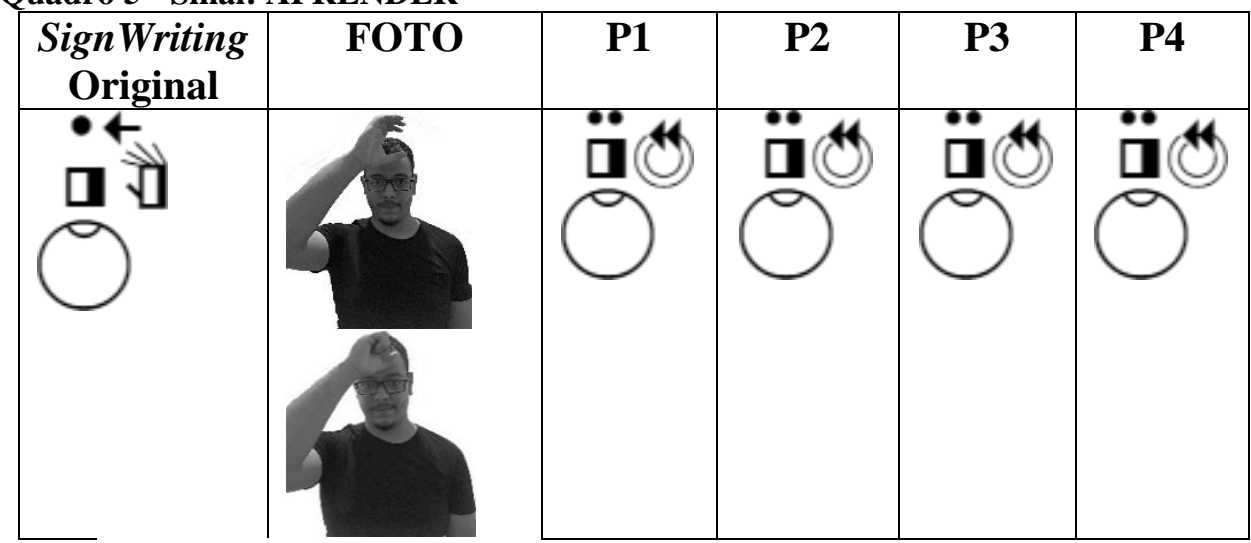

Fonte: Elaborado pelos autores (2017).

Para representação do sinal APRENDER em SignWriting, todos os participantes apresentaram a sinalização da mão direita esfregando a cabeça, movimento abrindo e fechando duas vezes, diferente do escrito original em SignWriting que começa com a mão localizada na cabeça em uma vez do movimento abrir e fechar. Os padrões das sinalizações pelos 
participantes tornam o sinal mais claro pois todos representaram o movimento duas vezes, diferente do sinal escrito original. As representações das sinalizações pelos participantes expressaram naturalmente a produção em Libras.

Quadro 6 - Sinal: CASTELO

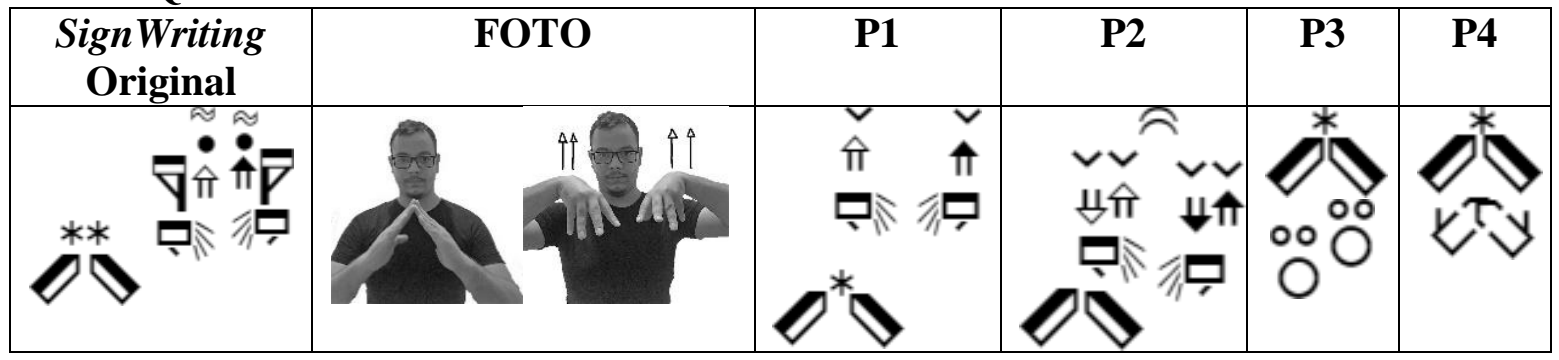

Fonte: Elaborado pelos autores (2017).

A representação do sinal CASTELO em SignWriting é composto com as duplas mãos representando configuração da mão aberta para fechada em movimento e articulação rápidos para cima, para abrir e fechar. P1 apresentou as duplas mãos juntas com movimentos para cima e para fechar. P2 apresentou as duplas mãos em movimentos para cima e para baixo e para fechar, de repente. P3 sinalizou CASA + ENSINO. P4 sinalizou ESCOLA. P3 e P4 expressaram Libras na compreensão da leitura nas pilhas do sinal escrito original representando o sinal composto CASA + TELHADO + CASTELO, mas eles reproduziram apenas o sinal CASA compondo com outros sinais. 
Quadro 7 - Sinal: BATISMO CINDERELA

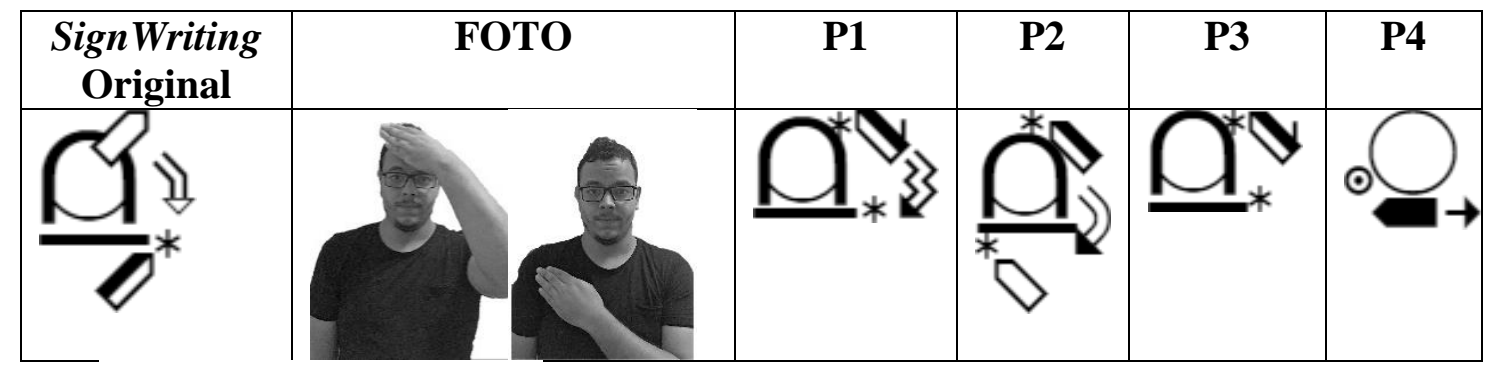

Fonte: Elaborado pelos autores (2017).

O sinal BATISMO CINDERELA em SignWriting tem a orientação da palma da mão esquerda para frente ao movimento para baixo, palma medial com posição de contato localizada no ombro à direita. P1 apresentou sinalização com orientação da palma medial com posição de contato localizada na cabeça, a mão direita curvada com movimento de flexão dos dedos e articulações com posição de contato localizada no ombro à direita. P2 apresentou a orientação de palma medial com posição de contato localizada na cabeça, palma virada para frente com movimento para baixo, mais posição de contato localizada no ombro à esquerda. P3 apresentou a mão direita na posição de contato localizada na cabeça até no ombro à direita. P4 sinalizou MORTE, não compreendeu. Então, P1 e P3 compreenderam o significado e as representações desses sinais podem ser considerados correspondentes ao sinal escrito original em SignWriting. A representação desse sinal escrito original está com a mão esquerda, os participantes representaram com mão direita e produziram expressões naturalmente. 
Quadro 8 - Sinal: MADRASTA

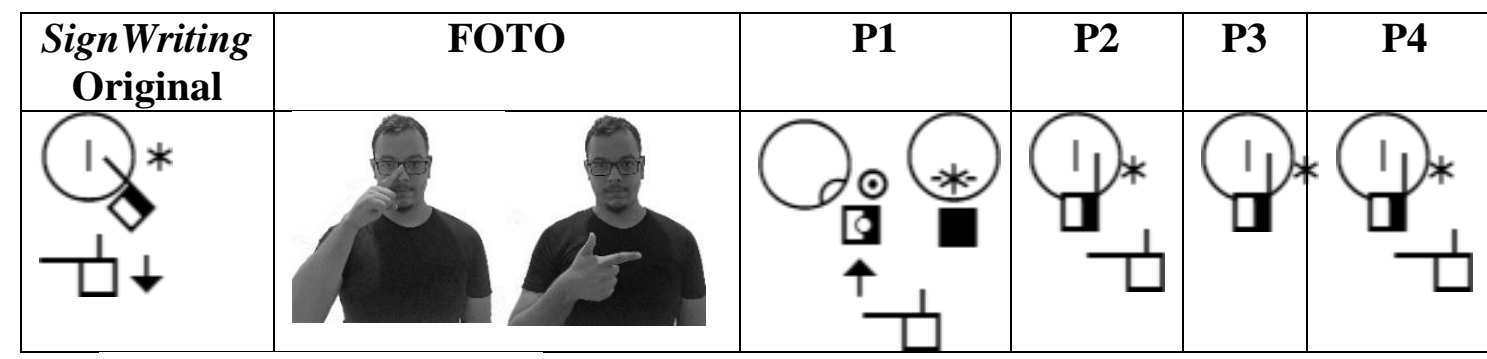

Fonte: Elaborado pelos autores (2017).

O sinal de MADRASTA em SignWriting teve variação linguística:

P1 sinalizou o sinal da própria região nordeste do Brasil, significado correto.

P3 sinalizou MÃE, mas faltou acrescentar um sinal para tornar-se MADRASTA. P2 e P4 fizeram sinal composto, apresentaram o contato, mas não apresentaram o movimento. Esse sinal escrito original do livro em SignWriting representa movimento para trás.

Quadro 9 - Sinal: BATISMO IRMÃ CAÇULA

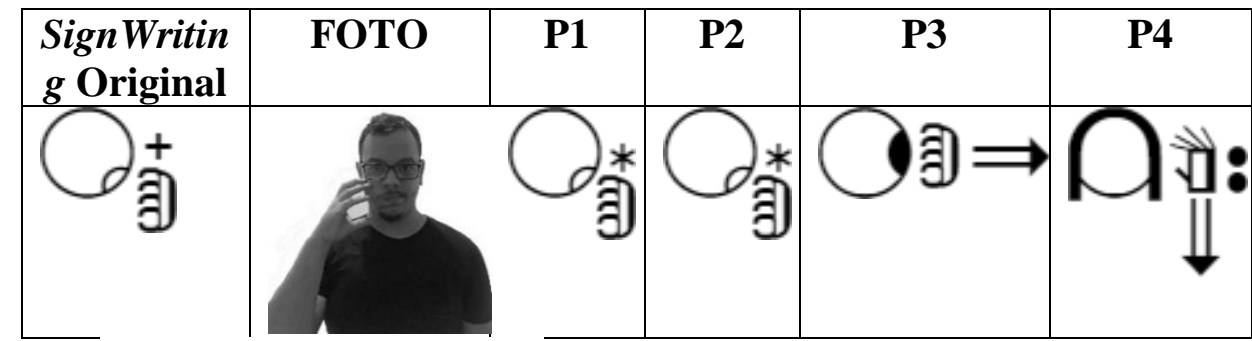

Fonte: Elaborado pelos autores (2017).

A representação do sinal BATISMO IRMÃ CAÇULA em SignWriting tem a orientação da palma medial mais o contato da mão direita curvada pegando na bochecha. P1 e P2 apresentaram a mão direita curvada em contato com a bochecha, compreenderam o significado. No entanto 
sinalizaram o contato "tocar", que no sinal escrito original representa "pegar". P3 apresentou a bochecha inflada com a mão direita em movimento para a direita, compreendeu o significado, somente a representação de sinalização tem movimento. P4 apresentou a mão direita em movimento para baixo, para abrir e fechar, de repente, não compreendido.

Quadro 10 - Sinal: TRABALHAR

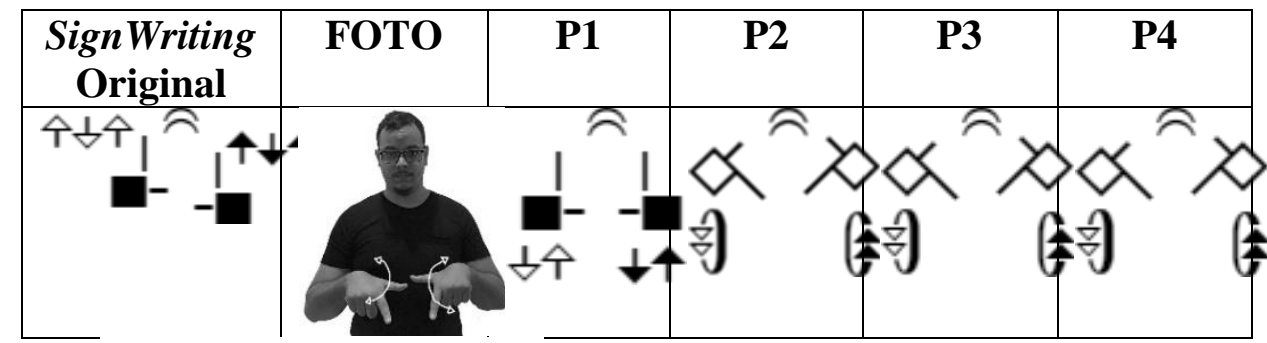

Fonte: Elaborado pelos autores (2017).

Nesse sinal de TRABALHAR em SignWriting, a orientação é da palma da mão para baixo com movimentos para frente e para trás, de repente. P1 apresentou a orientação da palma corretamente. P2, P3 e P4 apresentaram a orientação da palma da mão para frente em movimentos como se estivessem esfregando, de repente. Todos os participantes sinalizaram corretamente os significados em relação aos sinais escritos em SignWriting. 
Quadro 11 - Sinal: LAVAR PRATO

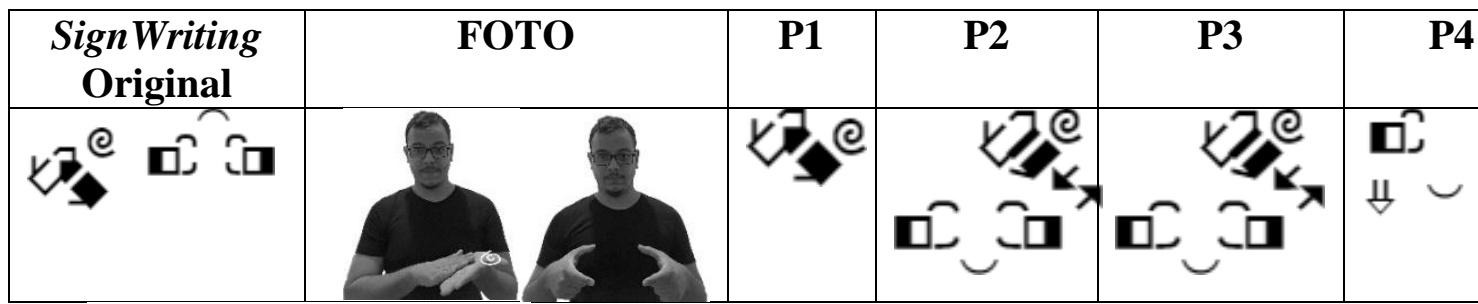

Fonte: Elaborado pelos autores (2017).

Com relação ao sinal de LAVAR PRATO em SignWriting, P1 apresentou sinalização da mão esfregando, mas não sinalizou o PRATO. P2 e P3 apresentaram a mão esfregando mais forte com movimentos para trás e para frente, de repente, sinalizando o PRATO. P4 não compreendeu e sinalizou ONDE. P2 e P3 apresentaram configuração de mão "a" que é diferente desse sinal escrito original que representa configuração de mão "b” em SignWriting.

Quadro 12 - Sinal: LAVAR CHÃO

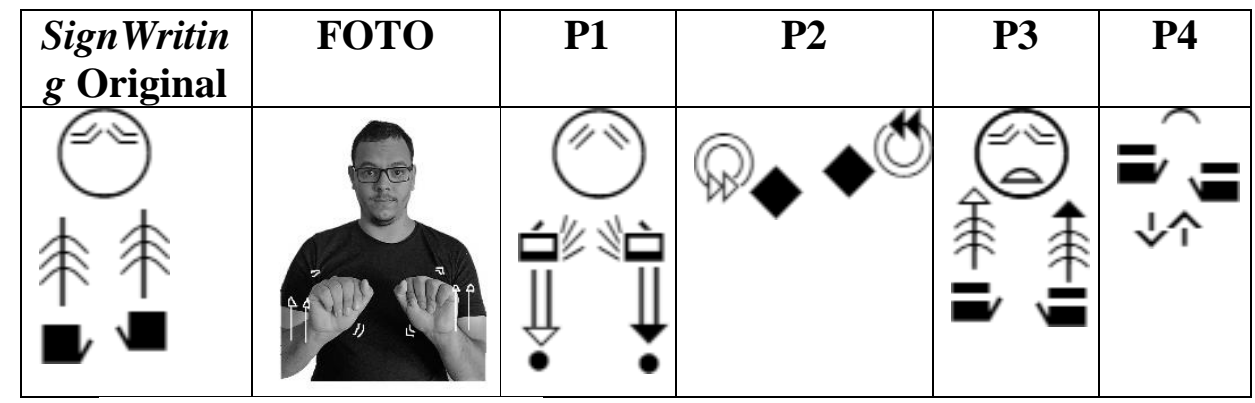

Fonte: Elaborado pelos autores (2017).

A pilha do sinal LAVAR CHÃO em SignWriting representou a orientação da palma da mão para trás, com movimento de vibração para frente e para trás, e mais a expressão facial "cansado", representou

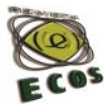


sobrancelha. P1 sinalizou CANSAR, compreendendo a expressão facial. P2 apresentou a orientação da palma da mão para trás com movimento de esfregar, não mostrou expressão facial. P3 apresentou a orientação da palma da mão para baixo com movimentos para frente e para trás, de repente, e mais a expressão facial "cansado", representou sobrancelha e boca, sinalizou correto. P4 sinalizou LAVAR-TANQUE e não compreendeu.

\section{CONSIDERAÇÕES FINAIS}

O objetivo desta pesquisa, conforme indicado anteriormente, é observar os alunos surdos se expressarem em Libras no processo da compreensão da leitura no livro literário em SignWriting, com a característica de expressão da pilha.

Esta investigação pode esclarecer para a análise dos dados que demonstra que os participantes apresentaram variadas sinalizações. Suas visualizações nas pilhas por SignWriting representam níveis de facilidade de leitura de determinado livro literário, particularmente sua compreensão funciona como alguns léxicos em SignWriting, mas para melhor compreender o processo de compreensão textual envolve a leitura visual. Os alunos surdos tendem a escolher textos literários de acordo com seu nível de conhecimento; logo, um aluno surdo com nível superior se interessa por textos de nível básico na compreensão dos signos que têm nas pilhas erros e acertos na leitura para cada produção literária, indicando a necessidade de uma melhor construção na escrita de sinais dentro da estrutura textual de livro literário como "Cinderela surda", e também da capacidade dos alunos 
surdos compreenderem o sentido real da escrita de sinais que transmite informação (de sua compreensibilidade).

Através desta pesquisa percebemos que a estrutura do texto do livro literário "Cinderela surda" através de SignWriting, deve qualificar a compreensão dos sinais escritos, pois não tiveram clara concordância no contexto da Libras e o sentido de leitura horizontal. Stumpf (2005) destaca que a estrutura-padrão do texto em SignWriting deve manter em coluna vertical no sentido de leitura. O livro literário "Cinderela surda" utiliza um sistema de escrita de sinais antigo, atualiza toda pilha por SignWriting, por isso os participantes visualizaram. Tem alguns sinais escritos com erros, por exemplo, o sinal "CARINHO”, o que leva o leitor à incompreensão do significado. Realmente algumas pilhas do livro não estão claras, por exemplo no sinal "BATISMO CINDERELA", P4 sinalizou a resposta errada, isso mostra que não compreendeu a representação do sinal escrito, porque não esclareceu a pilha. Ocorreu na pilha erros no contato, articulação e movimento, os sinais escritos originais: NOME, BONITO, GOSTAR, APRENDER, CASTELO e TRABALHAR tornam a escrita de sinais mais clara por visualização. A pilha da mão esquerda representa o sinal escrito no livro: NOME e BATISMO CINDERELA, mas os participantes sinalizaram com a mão direita. Visualizamos algumas partes dos sinais escritos originais por tabela da notação escrita, que mantiveram a mão direita. A escrita de sinais do texto padroniza a escolha da mão direita ou esquerda. A versão de livro literário tem escrita de Libras e português com duas traduções que estavam diferentes, dificultando a compreensão. A 
tradução simultânea da escrita de Libras e o português seria uma prática importante para facilitar o entendimento das duas línguas.

No momento, a anotação escrita da publicação de livro literário em SignWriting segue revisão por pesquisadores surdos, professores experientes e especialistas em escrita de sinais SignWriting, antes de sua publicação é fundamental lançar uma nova edição mais atualizada para padronizar e diminuir a ambiguidade e os possíveis erros da pilha tendo como conhecimento a estrutura do texto e do contexto, mantendo concordância no sentido da leitura.

Destacamos dois aspectos nesse sentido: o primeiro está relacionado à construção do conhecimento pelo próprio indivíduo; e o segundo considera o pensamento que a criança surda realiza, no processo de alfabetização nas atividades discursivas quanto à associação do conceito ao sinal. Nessa pesquisa, concluem os autores que há uma necessidade de modificar as práticas pedagógicas da alfabetização dos surdos.

A variação linguística ocorre no livro literário "Cinderela surda" no sinal escrito MADASTRA; são apresentados sinais das regiões gaúcha e nordestina no P1. Não houve modificação no sinal, podendo causar compreensão equivocada da leitura para a criança surda que vive nessas regiões e não sabe dessa variação linguística. Outros livros literários publicados devem adaptar vários textos mais populares de Língua Portuguesa para SignWriting, para que haja um entendimento correto por glossários, pois a escrita é secundária e a falada é primária, são distintas como a língua portuguesa falada e o escrito português também são diferentes. A análise apresentou que o signo escrito do livro literário de 
madrasta é do Sul e o aluno surdo percebeu que é variação linguística. P1 expressou que o sinal de madrasta é do Nordeste.

Por fim, a leitura de SignWriting é importante nas várias obras literárias; a transmissão do sistema de escrita de sinais para a comunidade surda desenvolve uma real compreensão da leitura e produção textual em língua de sinais na literatura surda. É importante ressaltar que comparando com as leituras em português, o SignWriting é um facilitador, por estar na primeira língua (L1) do surdo, sendo que o português como segunda língua (L2) impõe limites textuais, identifica prática bilíngue e os surdos têm que utilizar recursos como dicionários para conseguir compreender duas línguas no texto de forma holística.

\section{Referências}

BARBOSA, G. O. A arte de escrever em Libras.182 f. Dissertação

(Mestrado) -Universidade Federal de Santa Catarina (UFSC),

Florianópolis, 2017a.

. A etimologia de estudos de terminológicos referentes à escrita de sinais. Revista Virtual de Cultura Surda, n. 21, p. 1-27, maio 2017 b.

BARRETO, M.; BARRETO, R. Aquisição da leitura e escrita em

SignWriting. In: . Escrita de sinais sem mistérios. 2. ed. Salvador:

Libras Escrita, 2015. p. 86-94.

. As línguas de sinais $x$ a escrita. In: Escrita de sinais sem

mistérios. Belo Horizonte: Ed. do Autor, 2012. p. 32-39. 
BARROS, M. E. Escrita das Línguas de Sinais: proposta teórica e verificação prática. 199 f. Tese (Doutorado em Linguística) - UFSC, Florianópolis, 2008.

CAPOVILLA, F. C.; RAPHAEL, W. D. Dicionário enciclopédico ilustrado trilingüe da língua de sinais brasileira. 3. ed. São Paulo: Edusp, 2006.

CAPOVILLA, F. C. et al. Quando alunos surdos escolhem palavras escritas para nomear figuras: paralexias ortográficas, semânticas e quirêmicas. Revista Brasileira de Educação Especial, v. 12, n. 2, p. 203220, 2006.

CHOMSKY, N. Language and reponsability. New York: Pantheon, 1979.

FONSECA, J. J. S. da. Metodologia da pesquisa científica. Fortaleza: UEC, 2002.

GIL, A. C. Como elaborar projetos de pesquisa. 4. ed. São Paulo: Atlas, 2007.

HESSEL, C.; KARNOPP, L.; ROSA, F. Cinderela surda. 2. ed. Canoas: ULBRA, 2007. Disponível em:

<https://books.google.com.br/books/about/Cinderela_surda.html?hl=ptBR \&id=hp9MLsD6JXUC>. Acesso em: 18 maio 2017.

KOGUT, M. K. As descrições imagéticas na transcrição e leitura de um texto em SignWriting. 161 f. Dissertação (Mestrado em Linguística) UFSC, Florianópolis, 2015. 
LESSA-DE-OLIVEIRA, A. S. C. Libras escrita: o desafio de representar uma língua tridimensional por um sistema de escrita linear. Revel, v. 10, n. 19, p. 150-184, 2012.

LIVRINHO do Betinho. Série Livrinho do Betinho. Histórias em quadrinhos com temas transversais. Pelotas: Fanzona, 2002. [Coleção Garapa]. Disponível em:

<http://www.SignWriting.org/archive/docs1/sw0063-BR-LivRinHo.pdf>. Acesso em: 15 jul. 2017.

MINAYO, M. C. de S. (Org.). Pesquisa social: teoria, método e criatividade. Petrópolis: Vozes, 2001.

NOBRE, R. S. Processo de grafia da língua de sinais: uma análise fonomorfológica da escrita em SignWriting. 203 f. Dissertação (Mestrado em Linguística) - UFSC, Florianópolis, 2011.

OLIVEIRA, C. E. de; BOLDO, J. A cigarra surda e as formigas. Erechim, RS: Corag, 2004.

SILVA, F. I. da. Analisando o processo de leitura de uma possível escrita da língua brasileira de sinais: SignWriting. 114 f. Dissertação (Mestrado) - UFSC, Florianópolis, 2009.

SILVA, F. I. da. Ler em SignWriting: possibilidades de desenvolvimento cognitivo da criança surda. In: PERLIN, G.; STUMPF, M. R. Um olhar sobre nós surdos: leituras contemporâneas. Curitiba: CRV, 2002. p. 199211.

SOARES, M. Letramento: um tema em três gêneros. São Paulo: Autêntica, 1999. 


\section{STROBEL, K. L. Uma menina chamada Kauana. Belo}

Horizonte: Federação Nacional de Educação e Integração dos Surdos, 1997.

\section{STUMPF, M. R. Aprendizagem de escrita de língua de sinais pelo}

sistema SignWriting: línguas de sinais no papel e no computador. $330 \mathrm{f}$.

Tese (Doutorado) -Programa de Pós-Graduação em Informática na

Educação, Universidade Federal do Rio Grande do Sul, Porto Alegre, 2005.

. Transcrições de língua de sinais brasileira em SignWriting. In:

LODI, A. C. B. et al. (Org.). Letramento e minorias. Porto Alegre:

Mediação, 2012. p. 62-70.

\section{WANDERLEY, D. C. A leitura e escrita de sinais de forma processual}

e lúdica. Curitiba: Prismas, 2015.

i O sistema de escrita para línguas de sinais denominado SignWriting foi inventado por Valerie Sutton (STUMPF, 2005, p. 51).

${ }^{\text {ii }}$ Stumpf (2005 apud BARBOSA, 2017b, p. 60) informa que as pilhas são os símbolos (são derivados de elementos manuais) no uso de escrita de sistema SignWriting com uma configuração de mão, locação, movimento, e expressões não manuais constituindo um sinal escrito completo.

iii Alfabetização é exercício de aprendizagem da leitura e escrita (STUMPF, 2005).

iv Desde abril de 2009, quando nos propusemos, em projeto de pesquisa, a elaborar um sistema de escrita para Libras (Língua de Sinais Brasileira), o sistema SEL (Sistema de Escrita para Libras). Chegamos a uma versão satisfatória desse sistema em maio de 2011 (OLIVEIRA, 2014, p.150).

v 18 universidades públicas de diversos estados brasileiros usam o sistema SignWriting (BARBOSA, 2017a, p. 26).

vi No Brasil foram publicadas várias histórias infantis e outros materiais em Escrita de Sinais como: Uma menina chamada Kauana (STROBEL, 1997); Livrinho do Betinho (2002); As cigarras surdas e as formigas (OLIVEIRA; BOLDO, 2004)

vii Descrições imagéticas é o uso da gramática que se denomina classificador ou classificadores ou classificação manual, ela produz a possibilidade da imagem visual em Língua de Sinais como modifica as representações de ideias da pessoa ou objeto,

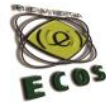


ISSN: 2316-3933

Online

relaciona iconicidade à complexidade do signo imagético tudo dentro da estrutura linguística, representando seu contexto de uso e conhecimento do mundo Surdo visual. (CAMPELLO, 2008 apud KOGUT, 2015).

viii HESSEL, Carolina; KARNOPP, Lodenir; ROSA, Fabiano. Cinderela surda. 2. ed. Canoas: ULBRA, 2007.

ix Notação escrita é registrar os sinais realizados pelos produzidos dos alunos surdos no processo da compreensão de leitura por meio de pilhas detalhando as unidades mínimas em SignWriting.

Este texto é de total responsabilidade de seus autores. 